\title{
MECHANICAL PROPERTIES OF POLYESTER MORTAR
}

\author{
Soumya Kumari.S ${ }^{1}$, K.Natarajan ${ }^{2}$, M.P.Manjunath ${ }^{3}$, Yashavantha. B.M ${ }^{4}$ \\ ${ }^{1}$ Assistant Professor, Department of Chemistry, Don Bosco Institute of Technology, Karnataka, India \\ ${ }^{2}$ Professor\& Head, Department of Chemistry, $R V$ College of Engineering, Karnataka, India \\ ${ }^{3} U G$ Student, Department of Civil Engineering, $R V$ College of Engineering, Karnataka, India \\ ${ }^{4} U$ G Student, Department of Civil Engineering, $R V$ College of Engineering, Karnataka, India
}

\begin{abstract}
Polymer mortars have become more popular as repair materials compared to conventional mortars. This paper reports the investigation on different mechanical properties of polyester mortar cured at ambient temperature and $80^{\circ} \mathrm{C}$. Unsaturated polyester resin, which is known for its cost performance efficiency is used to bind the aggregates. A comparative study was made on properties of polymers. It was found that thermal cured specimens exhibited improved compressive, flexural and split tensile strength compared to ambient cured specimens. However ambient cured samples exhibited a greater modulus than thermal cured samples. Since the polymer mortar exhibits high modulus of elasticity and ductility, it can be recommended as building materials for construction of earthquake retaining structure, repair works etc...
\end{abstract}

Keywords: Polymer mortar, polyester resin, compressive strength, modulus, flexural, split tensile.

\section{INTRODUCTION}

The use of polymers is considered to be a sign of progress and modern attitude in construction industry. Polymers are used as adhesives, modifiers, and matrix materials in concrete, hence can be used to replace the traditional binding agents [1-6]. Polymer composite materials are some of the youngest building materials. They are continually appearing with new and optimized properties as new combinations and formulations are developed.

Polymer mortar is a homogeneous mixture of fine aggregate and a polymer resin. The fine aggregates are bounded together by the polymer matrix. Polymer mortar is similar to conventional cement mortar as it contains fine aggregates, but Portland cement is completely replaced by polymer resin [78].When compared to the conventional mortar, polymer mortar exhibits additional advantages such as rapid hardening, improved resistance to chemical attacks and durability along with high mechanical properties [9-14]. Performance of polymer mortar depends on various factors such as resin content, types and mixed proportions and method of curing [15-18].The purpose of present research is to investigate the effect of different methods of curing on mechanical properties of polymer mortar.

\section{MATERIALS AND METHODS}

A resin and an accelerator are used as binder in the investigation.
The unsaturated polyester resin used in this investigation was Aropol 5334 which has medium viscosity and medium reactive. It is considered to have good mechanical properties and possess chemical resistance. The resin consists of $39 \%$ of styrene monomer as a viscosity modifier which also serves as a cross linking agent.

\subsection{Curing Agents}

Methyl Ethyl Ketone Peroxide (MEKP) is used as initiator to initiate the cross linking of unsaturated polyester resin. The radical formation would be accelerated by the addition of a suitable promoter. Cobalt napthenate $(\mathrm{CN})$ was used as an accelerator in the study.

\subsection{Fine Aggregate}

Natural river sand was used as fine aggregate in the preparation of polymer mortar. The specific gravity and fineness modulus of the sand used was 2.67 and 2.51 respectively. The grain size distribution curve of the fine aggregate is given in chart-1. It is evident from the figure that it is well graded sand.

\subsection{Unsaturated Polyester Resin}




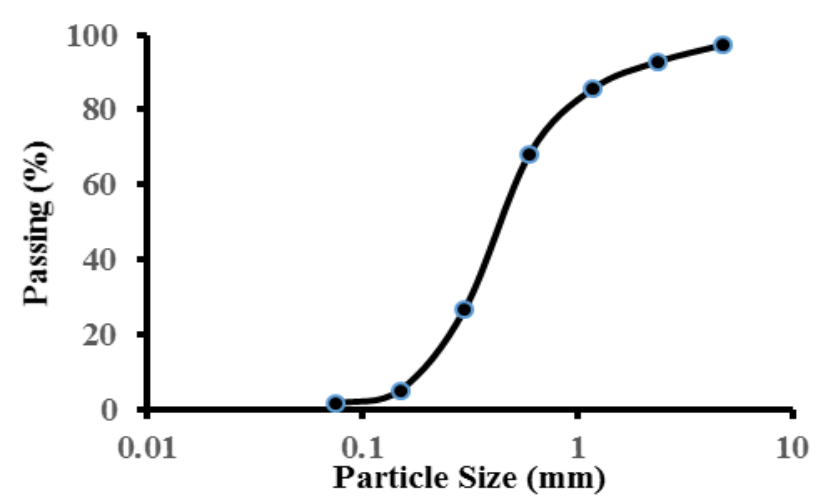

Chart -1: Particle size distribution curve

\subsection{Preparation of the Sample}

The polymer mortar has been prepared as per the procedure specified in IS 516:1959 [19]. The manufacturing process of the mortar consists of proportioning, mixing, compacting and curing.

Pre calculated fine aggregate was taken in mixing tray for which the resin was mixed with accelerator and initiator manually. Uniformly mixed mortar was used to cast cubes of size $50 \mathrm{~mm}$. Cylinders of diameter $150 \mathrm{~mm}$ and height $300 \mathrm{~mm}$ and beams of size $500 \times 100 \times 100 \mathrm{~mm}$ were casted as indicated in IS 516:1959 [19]. The specimens were cured at laboratory temperature and thermally cured at $800 \mathrm{C}$ for the duration of 2 hours before testing. The specimens were named as ambient cured thermally cured and respectively. The cured samples of mortar cube, cylinder and beam are shown in Fig 1. The cubes were tested for compression, cylinders for spilt tensile strength and beams for flexural strength.

For the polymer content below $6 \%$, it was found that the fresh polymer mortar was very harsh and could not bind the aggregates. But for $8 \%$ resin and above, there was considerable bond between the aggregates. The scope of the study was to restrict the percentage of polymer to 30 , as there were enough studies for resin $30 \%$ and above. Therefore, the percentage of polymer resin was varied between 8-30.
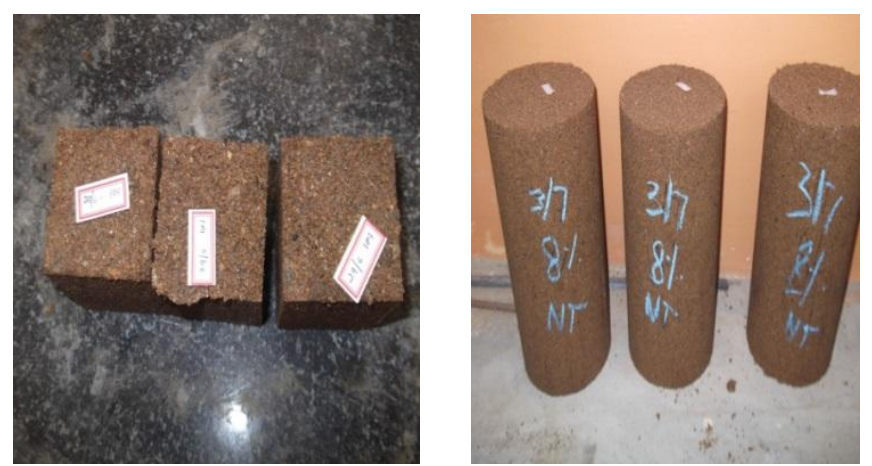

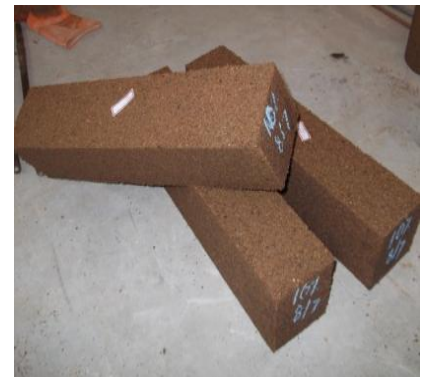

Fig-1: Polymer mortar cubes, cylinders and beam specimens

\section{RESULTS AND DISCUSSION}

\subsection{Dry Density Test}

The variation of the density of resin mortar with the percentage of resin is shown in the chart-2 at the age of 7 days. It was noticed that when the percentage of binder was less than 8 , there was no binding of the aggregates and mortar could not be made. Also the variation of density of mortar was not considered beyond $30 \%$ of resin due to economy. The density of polyester mortar varies from 1700 to $2194 \mathrm{~kg} / \mathrm{m} 3$ for various percentage of resin. It can be seen that the variation in the density is about $400 \mathrm{~kg} / \mathrm{m} 3$. The density is maximum when the percentage of resin was 25 .

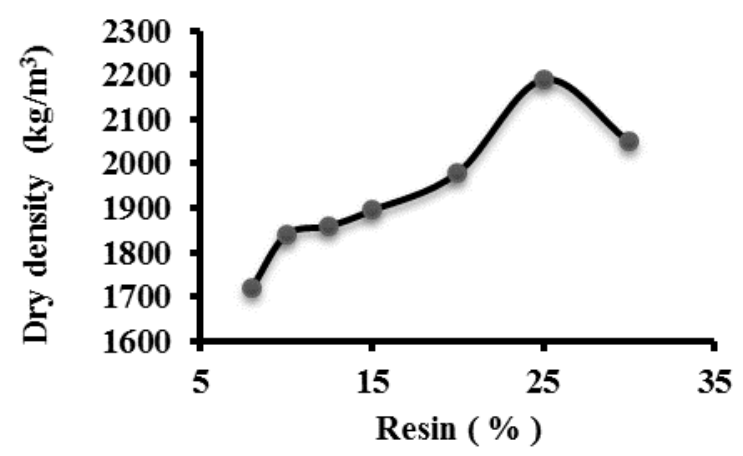

Chart -2: Variation of density with percentage of resin

\subsection{Water Absorption Test}

Polymer mortar specimens were tested for water absorption. The variation of water absorption of mortar with the percentage of resin is shown in chart -3 at the age of 7 days. The water absorption varies from 9.25 to $0 \%$. As the percentage of resin increases, water absorption decreases. It can be noted that the water absorption is nil above $25 \%$ resin. This property of mortar would be very much useful in marine and under water applications. 


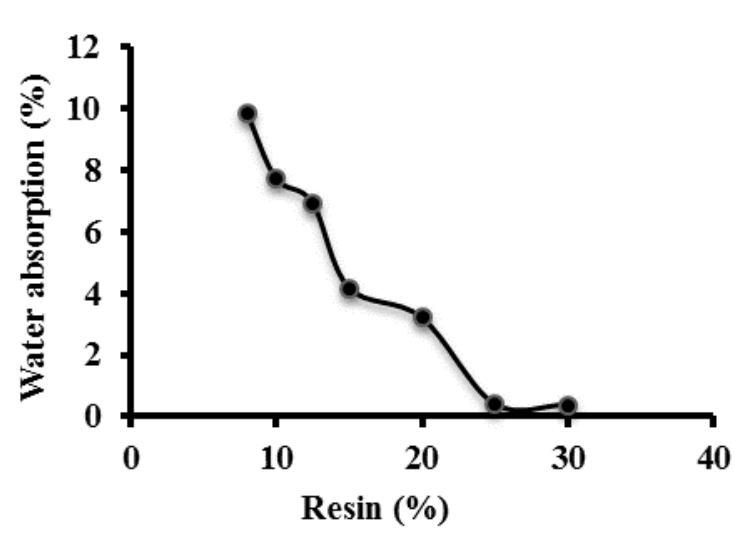

Chart -3: Water absorption with percentage of resin

\subsection{Compressive Strength}

The variation of compressive strength with different curing condition of polyester mortar specimens with percentage of resin is shown in chart-4 at the age of 7 days. Both type of mortars exhibited increase in strength with the percentage of resin. Thermal cured mortar developed higher strength compared to ambient cured samples by $80 \%$. The compressive strength of the mortar varies from 2.5 to $70 \mathrm{MPa}$ for various percentages of resin. For practical applications, the percentage of resin can be varied to get the required compressive strength from the chart-4.

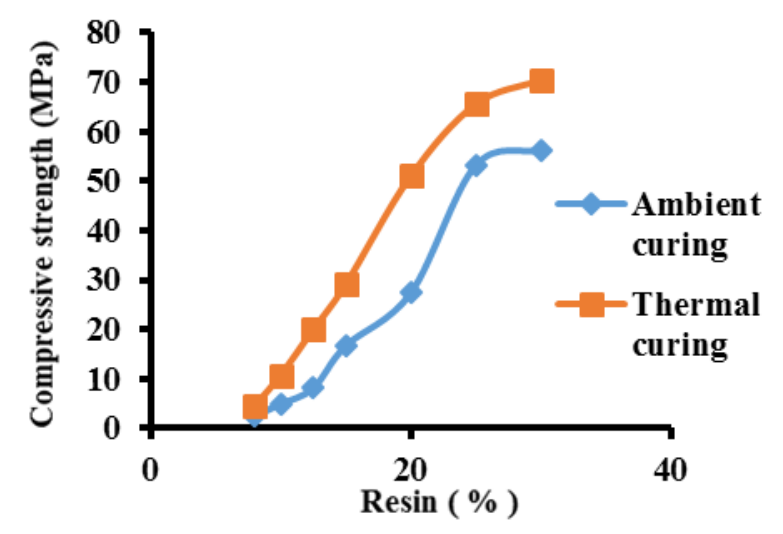

Chart -4: Variation of compressive strength with resin percentage

\subsection{Compressive Strength with Age}

It is very much necessary to study the strength development of a material with the age, when it is used in construction industry. The strength development was studied at the age of $1,3,7,14,21,28$ and 56 days. The variation of compressive strength with different curing condition of polyester mortar specimens with age is shown in chart-5 and 6 for 8 and $10 \%$ resin respectively.
It can be observed that the strength development of mortar is almost linear till the age of 7 days. The development of strength is not appreciable and almost saturated at this age. Hence for such polymer mortars, 7 days strength can be taken as reference for any specifications.

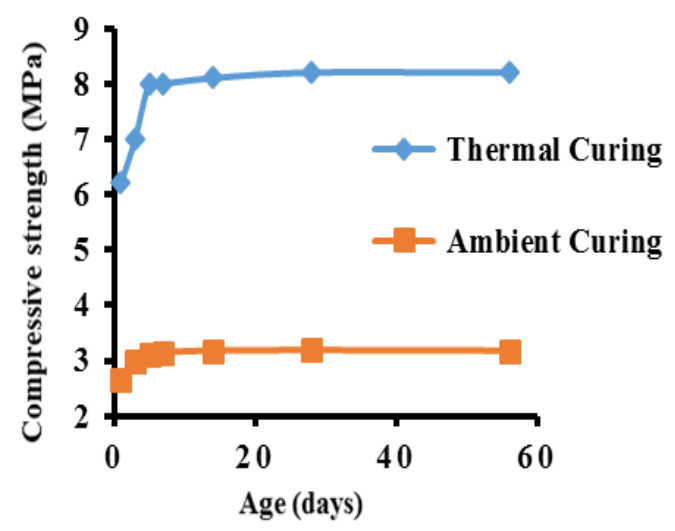

Chart -5: Variation of Strength with age for $8 \%$ resin

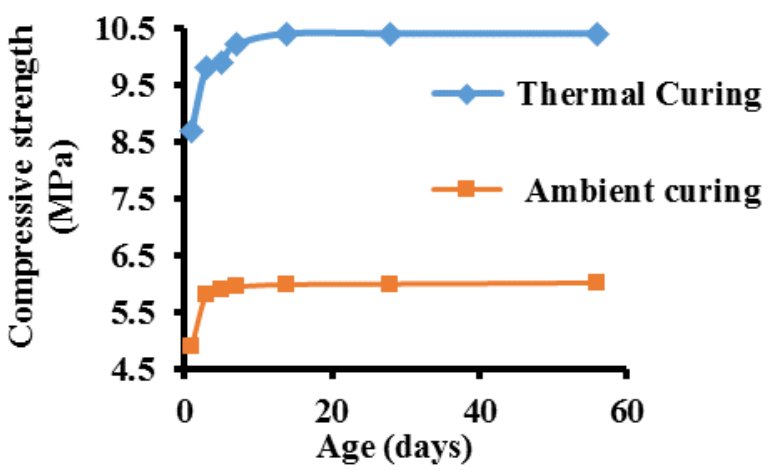

Chart -6: Variation of Strength with age for 10\% resin

\subsection{Split Tensile Strength}

It is important to know the split tensile strength of polyester mortar, if it is used as a repair material. The split tensile strength was found out for different curing conditions at the age of 7 days for $10 \%$ of resin. It is observed that split tensile strength is of thermal cured mortar was $40 \%$ higher than ambient cured mortar as indicated in chart -7 . However the split tensile strength is about 12.5 and $18 \%$ of compressive strength for thermal and ambient cured mortar respectively. 


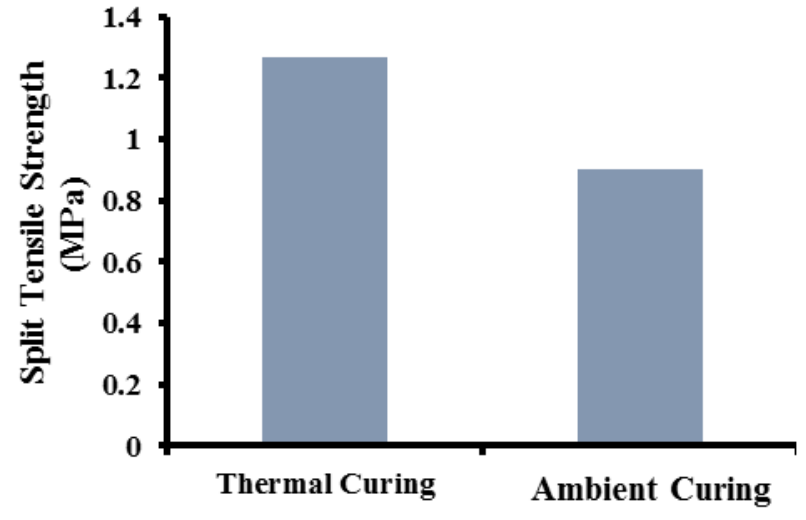

Chart -7: Variation of split tensile strength with method of curing

\subsection{Flexural Strength}

The Flexural strength is an important property of any mortar if it used in the construction of bridge decks, pavements etc. This test was conducted at the age of 7 days for the mortar with $10 \%$ resin. Flexural strength of thermal and ambient cured polymer mortar was found to be 2.52 and $1 \mathrm{MPa}$ respectively as shown in chart-8. The flexural strength is about 25 and $20 \%$ of compressive strength for thermal and ambient cured mortar respectively.

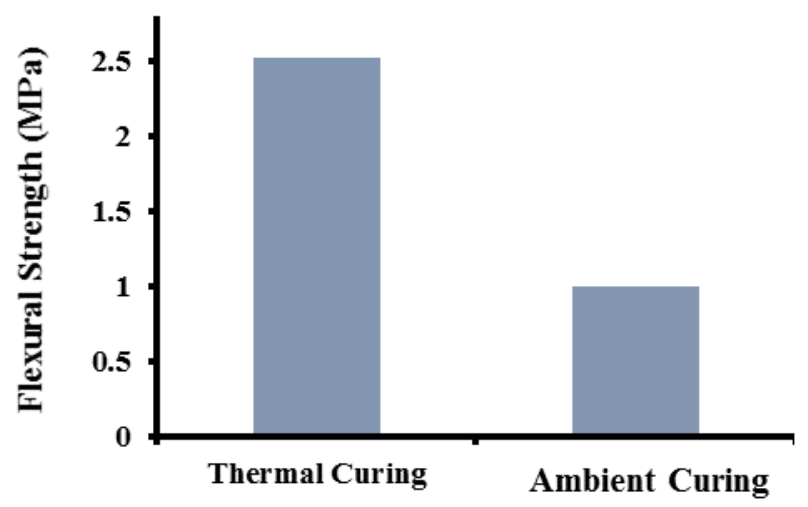

Chart -8: Variation of flexural strength with method of curing

\subsection{Modulus of Elasticity}

Modulus of Elasticity of polymer mortar was determined at the age of 7 days for the percentage of resin 8 and $10 \%$. The variation of stress and strain is indicated in chart 9 and 10 . It can be observed from these figures that the polymer mortar is more ductile compared to Portland cement mortar. This property of polymer mortar would be helpful in using it as a material in the construction of earthquake resistant structures. It can be noted that the ambient cure polymer mortar exhibited higher ductility and modulus of elasticity compared to thermal cured sample in both the cases considered for the study. The secant modulus of elasticity of mortars is indicated in chart 11.

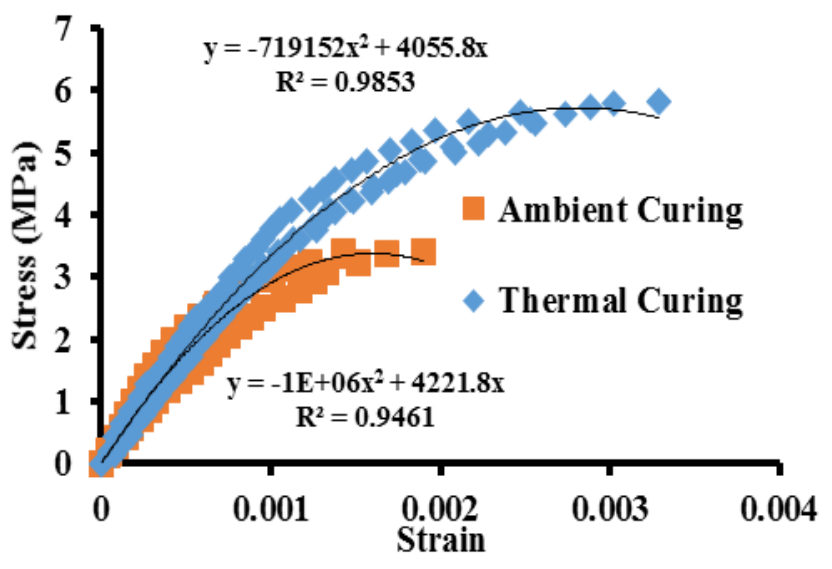

Chart -9: Stress-strain curve for $8 \%$ resin

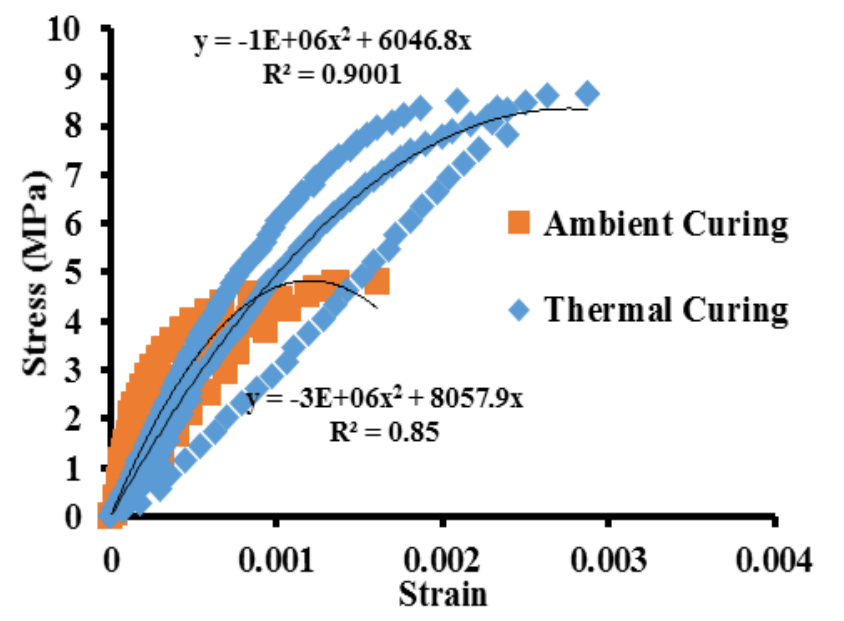

Chart -10: Stress-strain curve for $10 \%$ resin

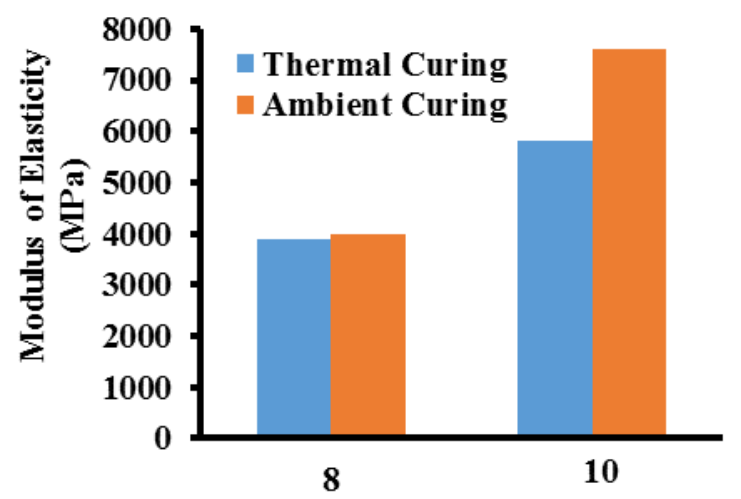

Chart -11: Modulus of Elasticity of polyester polymer mortar for different $\%$ of resin 


\section{CONCLUSIONS}

Based on the limited study on polymer mortar, the following conclusions may be drawn.

- It is possible to prepare polymer mortar using 8- 30 $\%$ polyester resin to get desirable properties.

- The thermal cured polymer mortar exhibited higher mechanical strength compared to ambient cured sample.

- However the ambient cured polymer mortar possesses higher modulus of elasticity and ductility compared to thermal cured mortar.

- Polymer mortar with polyester resin can be recommended for repair work and materials for earthquake resistant structure, bridges, pavements etc.

\section{ACKNOWLEDGEMENTS}

We express our sincere regards and gratitude to Dr. Radhakrishna, Associate Professor, Department of Civil Engineering of R.V College for his encouragement and guidance. We also extend our gratitude to the principal and management of Don Bosco institute of technology and R.V College of Engineering for their support to carry out research work.

\section{REFERENCES}

[1] Guneri Akovali, "Polymers in construction", Rapra Technology Ltd, Shrewsbury, [2005].

[2] Ohama .Y, Principle of latex modification and some typical properties of latex modified mortar and concrete adhesion; ACI Materials Journal, 84, issue-6, pages 511-518, [1987].

[3] Bordeleau D, Pigeon, M and Banthia, N, Comparative study of latex modified concrete and normal concrete subjected to freezing and thawing in the presence of deicer salt solution, ACI Materials Journal, volume 89, No-6, pages 547-553, [ 1992].

[4] Mandel, J.A and Said, S., Effect of the addition of an acrylic polymer on the mechanical properties of a mortar. , ACI Materials Journal, volume 87, issue-1, pages 54-61, [1990].

[5] Costas A Anagnostopoulos and Augoustinos C Anagnostopoulos, "Polymer-cement mortars for repairing ancient masonries mechanical properties", Construction and Building Materials, Volume 16, Issue 7, pages 379-384, [ 2002].

[6] Suresh Chandra Pattanaik, "Structural Strengthening of Damaged R.C.C. Structures with Polymer Modified Concrete", Proceedings of Workshop on Rehabilitation and Retrofitting of Structures, IIT Mumbai, [2009].

[7] Fowler D.W, "Polymers in concrete: where we have been and where are we going?" American concrete institute, international SP-214, pages 111-117, [2003].

[8] Marinela barbuta and Maria harja, "Experimental study on the characteristics of polymer concrete with epoxy resin”, Bul. Inst. Polit. Iaşi, t. LIV (LVIII), f. 1, [2008].

[9] M.Jamshidi and A.R.Pourkhorshidi, A comparative study on physical /mechanical properties of polymer concrete and Portland cement concrete, Asian journal of civil engineering vol.11, No.4, pages 421-432, [2010].

[10] M.C.S.Rebeiro, P.R.Novoa, A.J.M.Ferriera and A.T.Marques, "Flexural performance of polyester and epoxy polymer mortars under severe thermal conditions", Cement and Concrete composites, 26, pages 803-809, [2004].

[11] J.M.L.Reis, A.J.M.Ferreira, Freeze-thaw and thermal degradation influence on the fracture properties of carbon and glass fiber reinforced polymer concrete, Construction and building materials 20, pages 888-892, [2006].

[12] J.P.Gorniski, D.C.Dal Molin, C. S. Kazmierczak, Strength degradation of polymer concrete in acidic environments, Cement and Concrete composites29, pages 637-645, [2007].

[13] Hisham Abdel-Fattah, Moetaz M El-Hawary," Flexural behaviour of polymer concrete", Construction and Building Materials Volume 13, Issue 5, pages 253-262, [1999].

[14] Kyu-Seok YEON, "Polymer Concrete as Construction Materials." Int. J. Soc. Mater. Eng. Resour, Vol.17, No.2, [2010].

[15] Avci, A. Akdemir and H. Arikan, Mixed-made fracture behaviour of glass fibre reinforced polymer concrete, cement and concrete Res., 35(2), pages 243-247, [2005].

[16] J Mirza, M.S Mirza and R Lapointe, "Laboratory and field performance of polymer- modified cement-based repair mortars in cold climates, Construction and Building Materials," Volume 16, Issue 6, pages 365 374, [2002].

[17] Orsolya Ilona Németh, "Strength characteristics of polymer concrete in function of time and production conditions", Conference of Junior Researchers in Civil Engineering, pages150-157.

[18] M.C.S Ribeiro, P.R Nóvoa, A.J.M Ferreira and A.T Marques, "Flexural performance of polyester and epoxy polymer mortars under severe thermal conditions", Cement and Concrete Composites, Volume 26, Issue 7, pages 803-809, [2004].

[19] IS 516: Method of test for strength of concrete, (1959).

[20] C 469/ C 469M: Standard Test Method for Static Modulus of Elasticity and Poisson's Ratio of Concrete in Compression.

\section{BIOGRAPHIES}

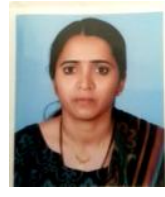

Soumya Kumari S, working as an assistant Professor in the Department of chemistry, Don Bosco Institute of Technology and a Ph.D scholar from R.V. College of Engineering. Currently working in the field of synthesis and 
characterization of interpenetrated network of polymer resin systems for polymer concrete applications

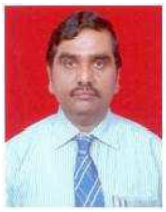

Dr. K. Natarajan is the inventor of TGPPD epoxy resin and NCCS cable seal. Two patent holder, he is the recipient of the prestigious National award for his invention of NCCS cable seal. He is currently the HoD of Chemistry Dept. \& Director, Advanced Polymer Material Lab (APML), R.V College of Engineering.

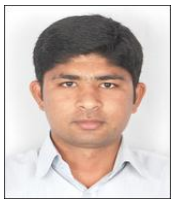

M.P Manjunath is pursuing his final year B.E at R.V.College of Engineering, Bangalore. He is doing research on polymer mortars. His areas of interests are Concrete Technology and Alternative building Materials.

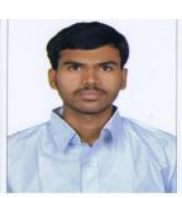

Yashavantha.B.M. is pursuing his final year B.E at R.V.College of Engineering. He is doing research on polymer mortars. His areas of interests are Construction Technology and Concrete Technology. 